\title{
Empirical Research on the Correlativity between Intellectual Capital and Technological Innovation Performance
}

\author{
Yang Zhilei \\ College of Management \\ Zhejiang Shuren University \\ Hangzhou, China \\ 13003620909@163.com
}

\author{
Wan Qing \\ College of Management \\ Zhejiang Shuren University \\ Hangzhou, China \\ Wanqing12345@tom.com
}

\begin{abstract}
Along with the development of intellectual capital theory, intellectual capital is becoming more and more important to economic development, and has become the main source of enterprise competitive advantage, which plays a very important role in promoting enterprise technological innovation performance. Through questionnaire investigation and SPSS data analysis to more than 173 Zhejiang small and medium sized manufacturing enterprises, the results can be drawn as: the three aspects of the intellectual capital (human capital, structural capital, and relationship capital) are positively related to enterprise technology innovation performance, in which the structural capital does the most, and then the human capital, the relationship capital does the least.
\end{abstract}

Keywords-Intellectual Capital; Technological Innovation Performance; Human Capital; Structural Capital; Relationship Capital

\section{INTRODUCTION}

With the globalization of economy today, the competition between enterprises growing. The focus of the competition is no longer on the resource, but gradually turned to technology, intelligence and knowledge. Intellectual capital has not only become the scarcest resource in enterprise competition and development, but the key resource in sustainable development also. Therefore, it's a realistic and pressing issue that lies in front of enterprises especially knowledge enterprise in China how to manage and utilize intellectual capital effectively and play the great effect of intellectual capital. So, the research on intellectual capital provides theoretical basis to give full play to the role of intellectual capital in economic growth and enterprise valueadded.

\section{LITERATURE REVIEW}

The concept of intellectual capital was first put forward by Economist Galbraith in 1967 who thought that intellectual capital was not only knowledge and pure intelligence, but should include all assets and way that can create value. Moreover, Economist Galbraith advocated that the intellectual capital should be a mental behavior.

American scholar Thomas Stewart, who published many articles about intellectual capital in the "fortune" magazine in the United States, first defined the intellectual capital as "All knowledge that the whole members of the company know and can gain competitive advantage in the market for enterprise"[1]. He also put forward the intellectual capital "H, $\mathrm{S}, \mathrm{C}^{\prime \prime}$ structure, that is the value of enterprise intellectual capital reflected in the human capital, structural capital and customer capital.

Review the research on intellectual capital home and abroad, the scholars and practitioners have different observation angles and research methods about intellectual capital elements, but academic circles basically accept the three dimensional structure model of intellectual capital, that is, human capital, structural capital and relationship capital. The intellectual capital mainly includes three characteristics: the first is embodied on the knowledge, skills and abilities in the staff, namely human capital; The second lies in organizational structure, rules and regulations, intellectual property rights, organizational culture, that is, structural capital; The third reflected in the brand, corporate reputation, customer satisfaction, called customer capital. Therefore, combined with a large number research on intellectual capital, the mainstream to describe intellectual capital is human capital, structural capital and relationship capital in general [2] (Bontis, 2001).

In recent years, scholars have found the fuzzy boundary between intellectual capital and technology innovation performance, they regard the intellectual capital as the guide and basis in studying technology innovation, and also regard technological innovation as a result in studying intellectual capital. The research project about intellectual capital to promote technical innovation supported by the British government finished by LEED City University in 2001 awared of the important impacts of intellectual capital on technological innovation. Bontis \& Richardson (2000) regarded that an organization's technological innovation ability was closely related to the organization's intellectual capital or the ability it used knowledge[3]. Intellectual capital was regarded as core competence that is dynamic and can accelerate the technological innovation. Lu (2004), by ways of DEA method, verified that the intellectual capital performance level is the key factor for enterprise to obtain larger innovation, intellectual capital can promote technological innovation, because it can turn knowledge into value[4]. Harrison \& Sullivan (2006) thought that the value created by intellectual capital include: (1) Profits, the income created by products and services; (2) Strategic position, such as market share and market control ability; (3) Innovation spillover from competitors; (4) Enhance customer loyalty; (5) 
Reduce the costs; (6) Improve productivity. Value promotion above reflects the role of innovation led by intellectual capital[5].

\section{RESEARCH DESIGN}

\section{A. Research hypothesis}

According to the literature above, propose the research hypotheses: intellectual capital has a positive effect on technological innovation performance which mainly including the follow specific hypotheses.

- High quality human capital is the premise of technological innovation. Human capital is the key to outstanding technology innovation performance, since the enterprise knowledge stock value-added rapidly by ways of continuous learning of the staffs, and finally break the limits of enterprise existing knowledge flow[6] (Zou Yan, Zhang XueHua, 2009). Thus, propose the research hypotheses H1: human capital has a positive effect on technological innovation performance.

- Structural capital includes process capital and innovational capital, in which the process capital provides support to the staffs, improves productivity, and ensures the quality of products and services. Learning organization that has good structure capital help to improve the efficiency of knowledge management, construct sharing and communication of culture, so as to improve the technological innovation performance[7] (Cohen \& Levinthal, 2004). Thus, propose the research hypotheses H2: Structural capital has a positive effect on technological innovation performance.

- Relationship capital promotes the technological innovation performance in three aspects. Firstly, good relationship capital is the source of technological innovation. Secondly, good relationship capital can reduce the risk of technological innovation. Thirdly, good relationship capital provides factors and resources for technological innovation. Thus, propose the research hypotheses H3: Relationship capital has a positive effect on technological innovation performance.

\section{B. Data and sample selection}

This research was carried out from early June to the end of October in 2012, taking the small and medium-sized private manufacturing enterprises at the different area of Zhejiang province as studying objects. It had mainly cover cities including Taizhou, Ningbo, Huzhou, Hangzhou and Wenzhou, etc. There were 210 questionnaires given out in total, among which 196 were returned. The returning rate is $93.3 \%$, among the returned questionnaires, there were 176 valid. The valid returning rate is $89.8 \%$, which was in accordance with the sample size of analytical method.

\section{Variable design}

The variables are designed through consulting a large quantity of literatures of related variables. In particular, the human capital is measured mainly by: Staff capacity and attitude, ability of management, staff stability, enterprise investment in human capital, etc. The structural capital is measured mainly by: Organizational structure, corporate culture, organizational learning, innovation and development, services and processes, etc. The relationship capital is measured mainly by: Customer oriented, customer loyalty, and partnership, etc. The technological innovation performance is measured mainly by: Financial performance, market ability, innovation and growth ability, etc.

\section{Research model}

According to the assumptions and setting above, the multiple linear regression model is built as in (1)

$$
\mathrm{Y}=\alpha_{1} \mathrm{X}_{1}+\alpha_{2} \mathrm{X}_{2}+\alpha_{3} \mathrm{X}_{3}+\varepsilon
$$

Among them, the "Y" is the technological innovation performance, $\alpha_{1}, \alpha_{2}, \alpha_{3}$ for constant, $X_{1}, X_{2}, X_{3}$ respectively for human capital, structural capital and relationship capital, $\varepsilon$ for residual.

\section{EMPIRICAL ANALYSIS}

\section{A. Reliability and Validity Analysis}

It adopts Cronbach's $\alpha$ value to test the reliability in our scale. Only higher consistency of values can ensure the measure of the variable, meeting the reliability requirements for this study. Require the Cronbach's $\alpha$ values of measure variables should be greater than 0.70 to meet the scale validity requirements.

The conclusion shows that the alpha value of intellectual capital is 0.948 , human capital 0.895 , structural capital 0.852 , relationship capital 0.914 , and the performance of enterprise technology innovation is 0.801 , the alpha value of all the variables in 0.801 above, the level of more than 0.7 standard, that is the social science scale reliability of acceptable range, high reliability, guarantee the quality of the measurement.

The test of the validity mainly is the content validity in this study, test whether the selected items can representative of the content or subject to be measured. Since this study is based on relevant theories, and takes the questionnaire design of existing empirical study as reference when it comes to the expression, set and the question amount of the items. The scales we used are in accordance with the existing ones in domestic and foreign literature and then revised combined with the research purposes of this article, thus providing higher content validity.

\section{B. Correlation analysis}

Correlation analysis refers to the degree of correlativity between two variables. Table I shows the results of correlation analysis among human capital, structural capital and relationship capital three dimensions and enterprise technological innovation performance. 
TABLE I. CORRELATION ANALYSIS

\begin{tabular}{|c|r|r|r|r|}
\hline variables & $\begin{array}{r}\text { Human } \\
\text { capital }\end{array}$ & $\begin{array}{c}\text { Structural } \\
\text { capital }\end{array}$ & $\begin{array}{c}\text { Relationship } \\
\text { capital }\end{array}$ & $\begin{array}{c}\text { Technology } \\
\text { innovation }\end{array}$ \\
\hline Human capital & 1 & $.805^{* *}$ & $.688^{* *}$ & $.649 * *$ \\
\hline Structural capital & $.805^{* *}$ & 1 & $.725^{* *}$ & $.706^{* *}$ \\
\hline Relationship capital & $.688^{* *}$ & $.725^{* *}$ & 1 & $.605^{* *}$ \\
\hline Technology innovation & $.649^{* *}$ & $.706^{* *}$ & $.605^{* *}$ & 1 \\
\hline Note: $* *$ In $\alpha=0.01$ level (double side) significant correlation. \\
\hline
\end{tabular}

As can be seen from the test results, at 0.01 significant correlation level, the dimension of human capital, structural capital and relationship capital and technological innovation performance are significant correlation. In the same time, According to table I, the three dimensions of intellectual capital are significant correlation each other at 0.01 significant correlation level.

The results verify the research hypothesis $\mathrm{H} 1, \mathrm{H} 2$ and $\mathrm{H} 3$ preliminarily, and now multiple linear regression analysis is adopted to test the correlativity between these variables more accurately.

\section{Multiple linear regression analysis}

Correlation analysis can only reflect the correlativity between variables, but it can't reflect the concrete influence degree between them. To further explore the relationship between these variables, multiple linear regression analysis is needed. Now, take technological innovation performance as dependent variable, and human capital, structural capital and relationship capital as independent variables to regression analysis, the results such as table II.

TABLE II. REGRESSION ANALYSIS

\begin{tabular}{|l|r|r|r|r|r|}
\hline \multirow{2}{*}{ Model } & \multicolumn{2}{|c|}{$\begin{array}{c}\text { Unstandardized } \\
\text { Coefficients }\end{array}$} & $\begin{array}{c}\text { Standardized } \\
\text { Coefficients }\end{array}$ & \multirow{2}{*}{ t } & \multirow{2}{*}{ Sig. } \\
\cline { 2 - 4 } & \multicolumn{1}{|c|}{ B } & Std. Error & \multicolumn{1}{c|}{ Beta } & & \\
\hline (Constant) & .142 & .238 & & .597 & .551 \\
\hline human & .213 & .108 & .182 & 1.974 & .050 \\
\hline structural & .494 & .107 & .447 & 4.604 & .000 \\
\hline relationship & .186 & .095 & .155 & 1.955 & .052 \\
\hline
\end{tabular}

The regression analysis results show that, the $\mathrm{R} 2=0.528$ in Model Summary, which is bigger the 0.5 significant correlation level, and the Sig. value is 0.000 in Anova analysis table, which is less than 0.01 level significant correlation.

And then, the regression analysis results in table II show that the Sig. value of Constant is 0.551 , which is bigger than the 0.5 significant correlation level, therefore, the multiple linear regression equation about these variables and technological innovation performance is standard equation. The Sig. value of human capital, structural capital and relationship capital is $0.050,0.000,0.052$ respectively, all are less than the 0.1 significant correlation level, and at the same time the B value these Sig. corresponding respectively to is $0.182,0.477,0.155$, Therefore, the multiple linear regression equation about these variables and technological innovation performance can be written as in (2)

$$
\mathrm{Y}=0.182 \mathrm{X}_{1}+0.477 \mathrm{X}_{2}+0.155 \mathrm{X}_{3}
$$

The "Y" is the technological innovation performance, $\mathrm{X}_{1}$, $\mathrm{X}_{2}, \mathrm{X}_{3}$ respectively for human capital, structural capital and relationship capital here.

\section{CONCLUSION}

Through the questionnaire investigation data analysis on 173 small and medium-sized private manufacturing enterprises in Zhejiang, the empirical results show that the entire three dimensions (human capital, structure capital and relationship capital) of intellectual capital have positive effect on enterprise technological innovation performance, that is, intellectual capital plays an important role on technological innovation performance. Thus, verify all the research hypotheses. Furthermore, the order of the effect strength that the three dimension of intellectual capital affect to technological innovation performance is: structure capital dose the most, human capital the second, and the relationship capital the least.

\section{REFERENCES}

[1] Stewart, Thomas A. "Your company's most valuable asset: intellectual capital". Fortune, vol 3, 1994 , pp.28 -33.

[2] Bontis, N. "Assessing knowledge assets: A review of the models used to measure intellectual capital". International Journal of Management Reviews, vol 1, 2001, pp.41-60.

[3] Bontis, Richardson. "Intellectual capital and the nature of business system by aligning stocks and flow". Journal of management Studies, 2000

[4] Liu Yajun. "The empirical research on the effects of intellectual capital, absorptive capacity and Technological innovation--based on the research of manufacturing enterprises". The doctorate thesis of Tianjin Industry University of management. 2010.

[5] Harrison, Sullivan. "Profiting from intellectual capital: learning from leading companies". Journal of Intellectual Capital. Vol 1, 2001, pp.33-46.

[6] Zou Yan, Zhang Xuehua. "The empirical research on the relationship of intellectual capital to technological innovation--based on the adjusted variable of absorption capacity”. Soft science. Vol 23, 2009, pp.71-76.

[7] Cohen, W \& Levinthal. "Absorptive capacity, A new perspective on learning and innovation". Administrative Science Quarterly, vol 35, 2004, pp. 128-152. 